\title{
On constant time to learn: A proposed modification of function'
}

\author{
GLORIA J. FISCHER \\ WASHINGTON STATE UNIVERSITY
}

The Ss learned a serial CVC list to criterion at a 2-sec rate. The $2 \mathrm{sec}$ was composed of one of four combinations of stimulus presentation time $\left(T_{p}\right)$ and interstimulus interval (ISI; i.e., $.25+1.75, .5+1.5,1+1$ or $1.5+.5 \mathrm{sec})$. Results were consistent with constant total learning time, $k=\left(T_{p}+I S I\right) N$ trials to criterion. Reported breakdowns in $k$ at fast $T_{p}(\leq$ .5 sec) were suggested to be due to the lack of an ISI or $\left(T_{p}+I S I\right)$ time sufficient to process item information adequately for storage.

With increased stimulus presentation time $\left(T_{p}\right)$, the number of trials (N) needed to learn pairedassociate (e.g., Bugelski, 1962) and serial lists (Fischer, 1966) was found to decrease in a negatively exponential manner. However, for relatively short exposures (between 1 and $17 \mathrm{sec}$ ) and relatively meaningful material (Brewer, 1967), total learning time remained constant, i.e., $\mathrm{T}_{\mathrm{p}} \times \mathrm{N}=\mathrm{k}$. Apparently a constant rate of learning underlies such a function. This assumption is supported by the finding that individual rates of learning remain invariant over list length (L) (Waugh, 1962) with time to learn per item increasing approximately as $\sqrt{\mathrm{L}}$ (Carroll \& Burke, 1965).

The present study asks the further question: Is constant time to learn simply a function of stimulus presentation time, as Bugelski (1962) suggested? Or is $k$ a function of a minimum time of stimulus presentation (e.g., the approximately $17 \mathrm{msec}$ sufficient for accurate perception of a stimulus; Friel \& Derogatis, 1965) plus additional time in the absence of the stimulus used, perhaps, to process stimulus information for at least temporary storage? In agreement with the latter possibility is Kaswan \& Young's (1963) conclusion that cognitive transmission may be slower than the exposure time necessary for accurate perception. Based on such an analysis, constant learning time (k) might be more accurately described by the function $\left(T_{p}+\right.$ an interstimulus interval, ISI) $N$, than by $T_{p} N$. The present study tested this possibility by varying $T_{p}$ through a range that has been found to produce variable total learning time (e.g., Mayzner et al, 1966), while holding ( $T_{p}$ + ISI) constant. Specifically, Ss learned serial lists with $\left(\mathrm{T}_{\mathrm{p}}+\right.$ ISI $)=2 \mathrm{sec}\left(\right.$ i.e., $\mathrm{T}_{\mathrm{p}}=.25, .5,1$, or $1.5 \mathrm{sec}$; $\mathrm{ISI}=1.75,1.5,1$, or $.5 \mathrm{sec}$, respectively). $\mathrm{T}_{\mathrm{p}} \mathrm{N}=\mathrm{k}$ predicts unequal $\left(T_{p}+\right.$ ISI $) N=k$ predicts equal total time to learn under such conditions.

\section{Method}

A random sample of 84 students from introductory psychology was required to participate in the experi- ment. The Ss were the first 64 of them to sign up, appear, then reappear two weeks later for a test of serial recall.

A 7-word practice list was: TWA, UFO, ABC, IOU, ESP, OAS, XYZ. Two 93-100\% Glaze lists were: (1) SUT, DOB, KAF, CEN, LIQ, ROP, MEX; and (2) GUL, NAV, PED, WAK, FUZ, HOM, BER. Following Wickelgren (1965) both 7-syllable lists were constructed so as to minimize acoustic similarity of initial and terminal consonants.

Equal numbers of Ss were randomly assigned to one of two lists and to one of four ( $T_{p}+$ ISI) exposure conditions. Lists were presented on a Lafayette drum, equipped with two timers. One timer regulated drum advancement $\left(T_{p}\right)$; the other regulated a solenoid operated shutter (ISI). There was no intertrial interval. Using the serial anticipation method Ss first learned to spell the practice list, then learned to spell either List 1 or 2. They were told they could anticipate (spell) a syllable at any time during the entire 2-sec interval. Trials were continued to a criterion of seven successive correct anticipations. Two weeks tone day later, each $S$ returned and was asked to write as many of the syllables as he could remember, in their correct order. Each $S$ was then asked to check the syllable he had considered to be the first one.

\section{Results and Discussion}

The number of trials to learn the serial list and the number of syllables recalled in their correct positions two weeks later are shown in Table 1. Both measures were subjected to 2 by 4 [list by $\left.\left(\mathrm{T}_{\mathrm{p}}+\mathrm{ISI}\right)\right]$ factorial design analyses of variance. Neither analysis revealed reliable sources of variation. Rather, Fs $<1.00$ were found for all $\left(\mathrm{T}_{\mathrm{p}}+\right.$ ISI) effects. Such findings for both serial learning and serial recall are clearly consistent with constant total learning time, $k=\left(T_{p}+I S I\right) N$. Other studies (e.g., Mayzner et al, 1966) have found a breakdown

Table 1. Serial Learning (Mean Trials to Criterion) and Serial Recall (Number Correct) Under Various Combinations of Stimulus Presentation Times $\left(\mathrm{T}_{\mathrm{p}}\right)$ and Interstimulus Intervals (ISI).

$$
\left(T_{p}+I S I\right) \text { in Sec }
$$

\begin{tabular}{lccccc} 
& $(.25+1.75)$ & $(.5+1.5)$ & $(1.0+1.0)$ & $(1.5+0.5)$ & $\mathrm{S}_{\overline{\mathrm{x}}}$ \\
\hline Learning & 11.3 & 10.2 & 12.7 & 11.6 & 1.2 \\
Recall & 2.1 & 1.9 & 1.9 & 2.4 & 0.5 \\
\hline
\end{tabular}


in $k$ at $T_{p} \leq .5$ sec. Present findings indicate that breakdowns in $k$ at such fast rates cannot be due to short $T_{p}$, per se. Instead, fast rates without an ISI may not allow sufficient time to process stimulus information adequately. Similarly, a breakdown in $\mathrm{k}$ with low meaningful material (Brewer, 1967) may reflect the need for greater processing time as stimulus information increases in difficulty.

References

BREWER. C. L. Presentation time, trials to criterion and total time in verbal learning. J. exp. Psychol., 1967, 73, 159-162.

BUGELSKI, B. R. Presentation time, total time, and mediation in pairedassociate learning. J. exp. Psychol., 1962, 63, 409-412.

CARROLL, J. B., \& BURKE, M. L. Parameters of paired-associate verbal learning: length of list, meaningfulness, rate of presentation, and ability. J. exp. Psychol., 1965, 69, 543-553.
FISCHER, G. J. Relation between presentation time, serial learning, and the serial-position effect. J. exp. Psychol, 1966, 72, 153-154.

FRIEL, C. M., \& DEROGATIS, L. The effect of nonpatterned sensory deprivation on visual recognition thresholds. Psychon. Sci., 1965, 3, 163-164.

KASWAN, J., \& YOUNG, S. Stimulus exposure time, brightness, and spatial factors as determinants of visual perception.J. exp. Psychol, 1963, 65, 113-123.

MAYZNER, M. S., TRESSELT, M. E., ADLER, S., COHEN, A., \& SCHOENBERG, K. M. Short-term retention, presentation rate, and number of display cycles. Psychon. Sci., 1966, 5, 317-318.

WAUGH, N. C. Length of series and the learning curve. Amer. $J$. Psychol, 1962, 75, 177-192.

WICKELGREN, W. A. Acoustic similarity and intrusion errors. J. exp. Psychol., 1965, 70, 102-108.

Note

1. Acknowledgement is due the very able assistance of Alida Spaans, who tested Ss, and Norman Braveman, who conducted a pilot study. 